\title{
BIAXIAL FATIGUE DESIGN PROCEDURE APPLIED TO WELDED PLATE STRUCTURES
}

\section{G. J. Moyar* and V. K. Garg**}

*Moyar Technical Services, Inc., 2051 Ogden Ave., Suite D, Downers Grove, IL 60515, USA
$* *$ Department of Mechanical Engineering, University of Maine, Orono, ME 04473, USA

\section{ABSTRACT}

Several biaxial fatigue theories are evaluated and the concept of fatigue several bianial is approach is illustrated in a equivalent uniaxial stress is applied. Thiously published fatigue data. These practical welded obtained from test beams with different web reinforcement fatigue dat

The derivation of the fatigue equivalent uniaxial stress cycle based on the The derivation of the fatigue equivary provides a conservative design tool modified maximum range of shear theortorily correlate fatigue data from different regions of a welded beam. It is recommended for use in nominal stress ferent regions as a practical means of making short-range extrapolations from existing data.

\section{KEYWORDS}

Fatigue; equivalent uniaxial stress cycle; welded beam; test data; range of shear stress; principal stress.

\section{INTRODUCTION}

A number of theories and design guidelines have evolved over the hears for the treatment of fatigue resulting from multiaxial loading [1-5], yet the great bulk of data is still for uniaxial loading. These guidelines range from simple nominal stress methods to more elaborate che practical designer, howwith associated nonlinear stress analyse ever is still largely dependent on uniaxial Modified Goodman Diagrams) for related body of stress data ( $0-N$ curves ans. The current design guidelines [8] many typical fabricated structural detar structures in North American interfor the fatigue analysis of freight car ap aproach.

In the fatigue design evaluation of conventional welded steel structural com- 
ponents, the designer tries to make use of fatigue "properties" which are derived from tests of structural weldments, subjected primarily to bending or axial loads. However, in most applications the loading is multiaxial. Fur thermore, even with single loading on a component, the state of nominal stres can be biaxial in the fatigue critical locations.

To handle this problem rationally and to use the conventional fatigue data base, the concept of fatigue equivalent uniaxial stress is used and several biaxial fatigue theories are evaluated. The approach is illustrated in a practical welded beam example, using previously published fatigue data $[9,10]$ The werting The existing fatigue data are extrapolated from one region of a beam to anoth concentration and weld details are similar. Furthermore, the study is rechicted to in-phese loading since a will provide the designer with a demastrated guideline for solving thercise general problem of structures subjected to externally applied combined loading.

\section{FATIGUE EQUIVALENT UNIAXIAI STRESS}

A designer often uses a Modified Goodman Diagram to determine the fatigue limit for a specific design detail and stress ratio $\mathrm{R}\left(=\sigma_{\min } / \sigma_{\max }\right)$ under a uniaxial stress state. This fatigue limit denotes the maximum stress, $\sigma$ which may be applied to the detail for an infinite number of times at that stress ratio, without producing a fatigue failure. The application of maximum stresses of any larger magnitude, if applied of ten enough, would eventually result in a fatigue failure of the part:

$$
\sigma_{\max }=\mathrm{b}+\mathrm{m} \sigma_{\min }
$$

where $b$ is the fatigue limit at $R=0$ and $m$ is the slope of the Goodman line.

On expressing Eq. (1) in terms of alternating stress, $\sigma_{a}\left[=\left(\sigma_{\max }-\sigma_{\min }\right) / 2\right]$ and mean stress, $\sigma_{\mathrm{m}}\left[=\left(\sigma_{\max }+\sigma_{\mathrm{m} i n}\right) / 2\right]$, one gets:

$$
\mathrm{b} /(1+\mathrm{m})=\sigma_{\mathrm{a}}+[(1-\mathrm{m}) /(1+\mathrm{m})] \sigma_{\mathrm{m}}=\sigma_{\text {ec }}
$$

where $\sigma_{e q}$ is the amplitude of the fatigue equivalent uniaxial stress for completely reversed loading.

The fatigue strength of a component subjected to combined stresses is investigated by expressing several fatigue failure criteria in terms of $\sigma_{e q}$ and $\mathrm{m}$. Fatigue failure criteria for combined stresses are based on physical concepts of failure, similar to those used for static combined stresses, 1.e., fatigue failure under combined stresses is envisioned when a limiting normal stress, under uniarial fluctuating stress. Th this study the following fat igue fail ure criteria are investigated:

1. Maximum Principal Stress [11]: The principal stresses vary so that their maximum values are $\sigma_{1}$ and $\sigma_{2}$, respectively. The maximum principal stress theory considers only the variation of the largest principal stress. Thus, for the
biaxial stress state, in which the largest principal stress varies from 0 to $\sigma_{1}, \mathrm{Eq} .(2)$ becomes:

$$
\sigma_{\text {eq }}=\sigma_{1} / 2+[(1-m) /(1+m)]\left(\sigma_{1} / 2\right)
$$

2. Modified Maximum Range of Shear Stress [1]: This theory assumes that the allowable amplitude of shear stress, $\tau_{a}$, on the plane of maximum shear stress
To the fatigue equivalent amplitude of shear stress $\tau$ eq, (on a plane for which the average normal stress is zero) minus an influence

列

$$
\tau_{\mathrm{a}}=\tau_{\text {eq }}-\mathrm{k} \sigma_{\text {na }}
$$

Tor the biaxial stress state, in which the maximum shear plane is perpendicufor the biaxial stress state, in which the varies from zero to peak, Eq. (4) can be written as:

$$
\tau_{\text {eq }}=\left(\sigma_{1}-\sigma_{2}\right) / 4+\mathrm{k} \quad\left(\sigma_{1}+\sigma_{2}\right) / 4
$$

(5)

two and using $\mathrm{k}=(1-\mathrm{m}) /(1+\mathrm{m})$.

$$
\sigma_{e q}^{\prime \prime}=2 \tau_{\text {eq }}=\left(\sigma_{1}-\sigma_{2}\right) / 2+[(1-m) /(1+m)]\left(\sigma_{1}+\sigma_{2}\right) / 2
$$

3. Maximum chanessed as:

$$
\sigma_{e q}^{\prime \prime \prime}=\frac{1}{2}\left(\sigma_{a 1}^{2}-\sigma_{a 1} \sigma_{a 2}+\sigma_{a 2}^{2}\right)^{\frac{1}{2}}+\rho\left(\sigma_{m 1}+\sigma_{m 2}\right) / 2 \sqrt{2}
$$

where $\sigma_{a i}=$ alternating component of the principal nominal stress, $\sigma_{\mathrm{mi}}=$ wean component mflut completely reversed loading.

By denoting $\rho$ in terms of $\mathrm{m}$ as $\rho=\sqrt{2}(1-\mathrm{m}) /(1+\mathrm{m})$ and using $\sigma_{\mathrm{ai}}=\sigma_{i} / 2$ and $\sigma_{\mathrm{mi}}=\sigma_{\mathrm{i}} / 2$ for the zero to peak loading, Eq. (7) can be rewritten as:

$$
\sigma_{\text {ë́q }}=0.5\left(\sigma_{1}^{2}-\sigma_{1} \sigma_{2}+\sigma_{2}^{2}\right)^{\frac{1}{2}}+[(1-\mathrm{m}) /(1+\mathrm{m})]\left(\sigma_{1}+\sigma_{2}\right) / 2
$$

t to the situation where the effect of mean stress is ignored. For a number o to the situation where the effect of mean stres recommended by Fisher [13]. Generally, however, $m$ will be a function of the number of cycles to failure. The dependence on mean stress at low to moderate stress levels (or long lives) s, nevertheless, slight as data in the region of low mean stress.

$$
\text { TEST DATA }
$$

The data used in the analysis were obtained from tests conducted at the University of Illinois and reported earlier $[9,10]$. The dimensions of the mild steel fabricated beam specimens, location of stiffners, and points of appl tion for loads are given in Fig. 1. The weld details are shown in Fig. 2. Type $B$ refers to continuous $3 / 16$ in. welds, whereas Type $C$ refers to noncontinuous or intermittent $3 / 16$ in. welds. The loads were appledral stress.

as to subject the flanges of the specimen to cycles of flults and the values of the principal Table 1 gives a summary of the test results and the values of the principal stresses computed
from Munse [14]

ANALYSIS OF DATA

The fatigue quivalent uniaxial stresses were calculated using the three fatigue fatigue failure criteria mentioned previously plotted against the number equivalent the tests, in Figs. 3, 4 and 5 . The 
least squares best $\mathrm{fit}$ straight 1 ine is drawn through the individual data sets. In deriving this "best fit", the data point corresponding to failure i the compression web was ignored. As may be observed from a comparison of Figs. 3, 4 and 5, the maximum range of shear theory appears to do the best jo of bringing the fatigue results of both $B$ and $C$ beam types into coincidence.

Another method of checking the ability of various theories to correlate fatigue data from different biaxial stress states is to derive the fatigue properties based on one set of data and then predict the cycles to failure for individual tests from the other set. For this purpose the data for the Type $\mathrm{C}$ beams, for which there are nore tests, were used to obtain the fatigue
properties, $\mathrm{b}$ and $\mathrm{k}$ used in conventional stress-life equation

$$
\mathrm{N}=\mathrm{N}_{\mathrm{e}}\left(\sigma_{\mathrm{e}} / \sigma\right)^{1 / \mathrm{k}}
$$

where $\mathrm{N}_{e}$ is the endurance limit, usually taken as 2,000,000 cycles, $\sigma_{e}$ is the fatigue limit or stress which produces failure in $\mathrm{Ne}$ cycles, $\mathrm{k}$ is the absolute value of the slope of the $\log \sigma-\log \mathrm{N}$ diagram.

The fatigue limit may be expressed in terms of the limit for 0 to tension cycling, $b$, the stress ratio, $R$, and the slope of the Modified Goodman Diagram as:

$$
\sigma_{\mathrm{e}}=\mathrm{b} /(1-\mathrm{mR})
$$

From Type $C$ data on the $\sigma-N$ diagrans of Figs. 3, 4 and 5, the fatigue properties $k$ and $\sigma_{e}$ or $b$ (fatigue strength at $2,000,000$ cycles) were obtained from a least squares linear regression analysis and tabulated below for the three fatigue theories.

$$
\text { Theory }
$$

Maximum Principal Stress

Modified Max. Range Shear Stres

Maximum Octahedral Shear Stress

$\begin{array}{ll}\frac{\sigma \mathrm{e}}{18.60} & \underline{\mathrm{k}} \\ 28.20 & 0.19 \\ 24.86 & 0.22\end{array}$

A comparison of the corresponding predictions for the three theories versus the observed cycles to failure for the type $\mathrm{B}$ beam specimens is provided in Table 2. The mean and standard deviation of the difference of predicted minus observed cycles to failure were calculated anc the maximum shear range theory appears more satisfactory in that the mean difference in prediction and observation is smaller. Overall, the maximum principal stress theory is the least conservative; that is, it predicts longer lives than observed.

\section{GENERALIZATION}

In order to gain a better understanding of the mean stress effect and perform ance of the fatigue criteria in general for beam type structures, the fatigue equivalent uniaxial stresses from Iqs. (3), (6) and (8) are expresser

$$
\text { Since } \quad \sigma_{1}=(\sigma / 2)\left(1+\sqrt{1+n^{2}}\right)
$$$$
\text { and } \quad \sigma_{2}=(\sigma / 2)\left(1-{\left.\sqrt{1+n^{2}}\right)}^{2}\right.
$$

and

where $\sigma=$ nominal bending stress at the failure location and $\eta=2 \tau / \sigma, \tau=$ nominal shear stress at failure location. On substituting Eqs. (11) and (12) into Eqs. (3), (6) and (8), one gets

$$
2\left(\sigma_{\mathrm{eq}}^{\prime} / \sigma\right)=\left(1+\sqrt{1+n^{2}}\right) /(1+n)
$$

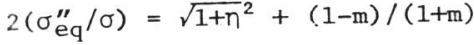

$$
\begin{aligned}
& 2\left(\sigma_{\text {eq }}^{\prime \prime \prime} / \sigma\right)={\sqrt{1+0.75 \eta^{2}}}^{2}+(1-\mathrm{m}) /(1+\mathrm{m})
\end{aligned}
$$

plotted in Fig. 6 to show the relationships between equivalent uniaxial stress and normalized shear stress for a* - 1.0. Fig. 6 is convenient for design purposes to obtain the fatigue equiWalent uniaxial stress for any location in the beam when the nominal 6 that and shear stress are known at that location. It may be seen in Fig. 6 thas Wie maximum principal stress theory becomes increases.

\section{DISCUSSION}

n the original presentation of these fatigue data Munse [10] noted that all the test wherved that the web failures initiated at locations where the flexural stress was considerably below the maximum. He also observed that the crack neemed to propagate in a direction perpendicular to the maxincipal tensil tensile stress and, therefore, conclude location would correlate the data stres failure section.

While it is true as Munse stated that "one should take into account the effect While it is true as Munse stated the stress in the web of the member" [10], it of shear upon the principaled range of shear or octahedral shear theory is th believed that the morvative prediction of fatigue initiation than the maximum principal stress theory.

\section{CONCLUSION}

The derivation of the fatigue equivalent uniaxial stress cycle based on the modified maximum range of shear theory provides a conservative design tool that has been demonstrated to satisfactorily correlate fatigue data from different regions of a weld fabricated beam. It is recommended for use in nomina] stress design approaches, not as a fundamental new theory, but as a practical means of making short range extrapolations from

crack initiation in representative weldme important nominal biaxial stress range

This approach takes into account the important nominal biaxial stress rang differences that may exist from one fatigue-critical location to another. However, its implementation still depends on crack initiation data rom local ventional tests with similar weldment details and matically equivalent. It is not offered as an a1stress concentrations are basically equivalented crack initiation predictternate or replacement method for the more advanced crack iniculated or ion techniques. The advanced tundamental fatigue propermeasured local strains configurations.

The The success a biantisin stress in correlating fatigue resch relating the plastic slip mechanisms of in view of fatigue crack initiation tatigue involving crack propagation would require analysis of the scope of this paper. 


\section{ACKNOWLEDGEMENTS}

William H. Munse, Professor (emeritus) of Civil Engineering of the University of Illinois, has kindly provided us with much additional information regarding his previously published work on which our demonstration of data correlation depends. We offer him our sincere thanks while taking responsibility for any errors or misinterpretations that may be found in our analysis of his experiments.

We also express our appreciation to the Association of American Railroads, especially Mr. Keith Hawthorne, Mr. James Lundgren, Mr. Roy Allen and Dr. Roger Steele.

\section{REFERENCES}

1. Little, R.E., and R. W. Little (1965), "Analysis of Two Dimensional Cyclic Stress", Ninth Midwestern Mechanics Conference, Madison, Wis.

2. Mitchell, L. D., and D. T. Vaughn (1974), "A General Method for the Fatigue-Resistant Design of Mechanical Components, Part Graphical; 75 -WA/DE-5.

3. Kececioglu, Dimitri, Louie B. Chester, and Thomas M. Dodge (1974) "Combined Bending-Torsion Fatigue Reliability of AISI 4340 Steel "Combined Bending-Torsion Fatigue Reliability of

4. Miller, W.R., K. Ohji, and J. Marin (1967), "Rotating Principal Stress Axes in High-Cycle Fatigue", ASME Journal of Basic Engineering, 3,

pp. $76-80$
Marin, J. Combine (1965), "Interpretation of Fatigue Strengths for London, England.'

6. Socie, D. F. (1977), "Fatigue Life Prediction Using Local Stress-Strain Concepts", Experimenta1 Mechanics, SESA, 2, pp. 50-56.

7. Kelley, F. S. (1980), "A General Fatigue Evaluation Method", ASME Journal of Pressure Vessel

8. AAR (1979), "Fatigue Analysis Methods", Manual of Standards and Recommended Practices, section C - Part II, Volume I, M-1001.

9. Wilson, W. M. (1948), "Flexural Fatigue Strength of Steel Beams", University of Illinois Bulletin, No. 33, Vol. 45, Urbana, Illinois.

10. Munse, W. H. (1964), "Fatigue of Welded Steel Structures", Editor La Motte Grover, Welding Research Council, New York, N.Y.

11. Marin, J. (1962), Mechanical Behavior of Engineering Materials, Prentice - Hall, Inc., Englewood Cliffs, N.J.

12. Fuchs, H. O. and R. I. Stephans (1980), Metal Fatigue in Engineering,

13. Fisher, J. W. and T. T. Yen (1979), "Minimizing Fatigue and Fracture in Steel Bridges", ASME Structural Integrity Technology, p. 155.
TABLE 1 Summary of Test Results

Flexural to Fracture

Stress Failure Location

Specimen

YPE $(\mathrm{AA}-)$

(ksi) (millions)

tiffener
tifation

$29(0) B^{*}+\mathrm{SB}^{* *}$

$30(0) B+S$

$31(0) B+S B$

$41(0) B+S B$

$43(0) B+S B$

TYPE C:

$13(0) \mathrm{A}+\mathrm{SC}$

14 (0) A+SC

15(0) $A+S C$

$44(0) B+S C$

$45(0) \mathrm{B}+\mathrm{SC}$

$46(0) B+S C$

$57(0) B+S C$

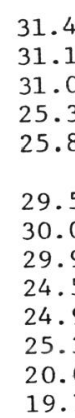

0.6278

0.4467

0.5236

1.1103

**** 2

at Pt. of Crack

initiation (ksi)

Max. Min.

$\begin{array}{ll}30.71 & -9.77 \\ 34.89 & -8.45\end{array}$

$\begin{array}{ll}34.89 & -8.42\end{array}$

$24.76-7.89$

$22.08-9.18$

$22.3 \quad-12.54$

$26.2-11.03$

$22.6 \quad-12.72$

$17.42-11.07$

$17.71-11.25$

$17.99-11.43$

$17.65-7.28$

$17.39-7.18$

NOTES:

* $B$ or $A$ in this position of specimen identif

* beam welding sequesition of specimen identification code refers to beam

stiffener type. See Fig. 2.

**

(in Millions) of Type B Theories

\begin{tabular}{|c|c|c|c|c|c|c|c|}
\hline$\underset{\text { SPEC. }}{\text { SPE. }}$ & $\begin{array}{l}\text { OBS. } \\
\text { CYCLES }\end{array}$ & $\begin{array}{r}\text { MAX. PR } \\
\text { STRESS T }\end{array}$ & $\begin{array}{l}\text { IN. } \\
\text { HEORY }\end{array}$ & $\begin{array}{r}\text { MAX. SHI } \\
\text { STRESS TI }\end{array}$ & $\begin{array}{l}\text { EAR } \\
\text { CHEORY }\end{array}$ & $\begin{array}{r}\text { MAX. } \\
\text { STRESS } \\
\end{array}$ & $\begin{array}{l}\text { CT. } \\
\text { IEORY }\end{array}$ \\
\hline $\begin{array}{l}\mathrm{AA}- \\
\mathrm{SC}\end{array}$ & FAIL. & PREDICT - & DIFF. & PREDICT. & - DIFF. & PREDICT. & DIFF. \\
\hline $29(0) \mathrm{B}$ & 0.6278 & 0.1426 & -0.4852 & 0.3868 & -0.2410 & 6 & -0.2822 \\
\hline $30(0) \mathrm{B}$ & 0.4467 & 0.07 & -0.37 & 0.2836 & -0 & & 112 \\
\hline $\begin{array}{l}31(0) \mathrm{B} \\
41(0) \mathrm{B}\end{array}$ & 0.52 & 0.0 & -0.44 & 0.2 & -0.2352 & 0.2 & -0.2837 \\
\hline $\begin{array}{l}41(0) B \\
43(0) B\end{array}$ & 1.1103 & 0.4 & -0.6665 & 1.0 & -0.08 & 38 & -0.1915 \\
\hline $43(0) B$ & 1.2719 & 0.8111 & -0.4608 & 1.2522 & -0.0197 & 1.1994 & -0.0725 \\
\hline & & DEV. & $\begin{array}{r}-0.4871 \\
0.1086\end{array}$ & & $\begin{array}{r}-0.1486 \\
0.0962\end{array}$ & & $\begin{array}{r}-0.2082 \\
0.0864\end{array}$ \\
\hline
\end{tabular}



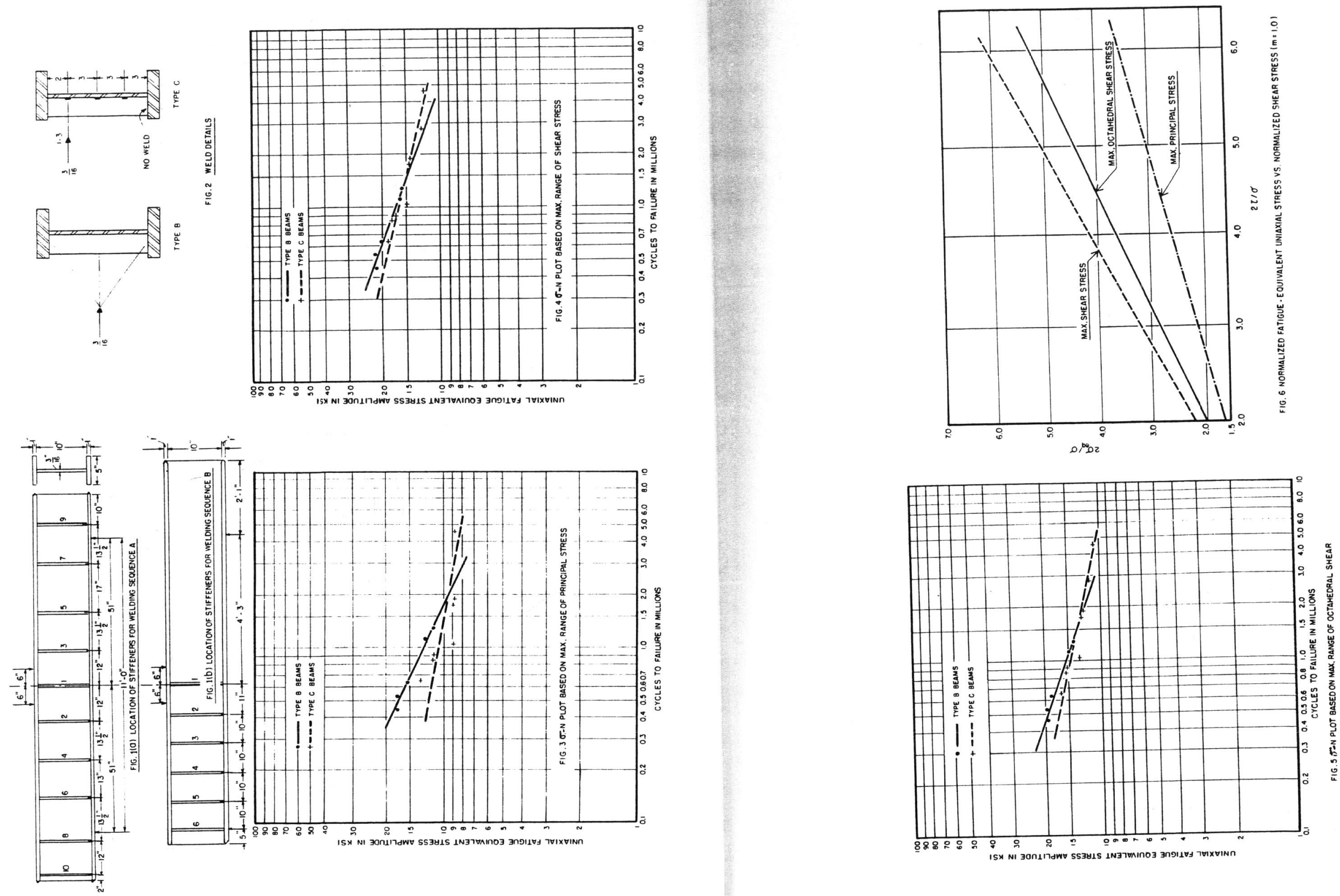